\title{
MEASUREMENT OF SOIL COLOR
}

\author{
J. A. Shields, R. J. St. Arnaud, E. A. Paul, and J. S. Clayton \\ Saskatcbewan Institute of Pedology, University of Saskatcbewan, Saskatoon, Saskatchewan
}

Received July 2, 1965

\begin{abstract}
The color of cultivated surface samples from Chernozemic and Gray Wooded soils were measured by visual and spectroreflectance methods. Variations in visual color measurements among different observers were of sufficient magnitude to represent serious errors in the application of the soil color criteria outlined in the Canadian soil classification system.

Spectroreflectance measurements facilitated the accurate measurement and characterization of the Munsell renotations of Chernozemic and Gray Wooded soils sampled within their respective soil zones. The ratio of renotation value : renotation chroma of the Chernozemic samples (air-dry) were distinctly lower than those of the Gray Wooded samples. The presence of moisture caused a greater decrease in the renotation value of the Gray Wooded samples than it did in the Chernozemic samples. The renotation hue of most of the measured samples occurred midway between the $10 \mathrm{YR}$ and $2.5 \mathrm{Y}$ hue charts currently available in the Munsell soil color chart series.

Color measurement of cultivated surface soil samples taken within the various soil zones of Saskatchewan indicated discrepancies between their renotation values and the color criteria currently suggested by the National Soil Survey Committee of Canada for the respective soils at the Order and Great Group
levels.
\end{abstract}

\section{INTRODUCTION}

Color is one of the most obvious and often the most significant characteristic of the soil. Surface color which differs from that of the parent material is usually a reflection of the processes operative during soil formation and may also indicate other factors such as excess salinity or erosion. The importance of color is demonstrated by its definitive role in the classification of Canadian soils (11), particularly Chernozemic soils which are subdivided at the Great Group level on the basis of significant differences in the darkness in color of the A horizon. It is apparent therefore that relatively slight differences in the color or color pattern of the surface horizons are significant in classifying soils into one or another different Great Groups.

Soil color has been measured by spinning Maxwell discs (4), visual color analyzers (20), recording spectrophotometers (13), and by visual comparison to secondary color standards (16). The results of color measurement have been recorded in terms of exposed areas of color discs (4), dominant wavelength and purity $(3,20)$, C.I.E. color notations $(13,15)$, and Munsell notations $(7)$. It is generally concluded $(10,16,19)$ that soil colors are most conveniently measured by comparison with secondary color standards. The present method has evolved from the color charts prepared by the U.S.D.A. in 1941 (8), and later by the Munsell Color Company $(9,10)$.

It is known (19) that soil colors are rarely a perfect match for any of the chips on the Munsell soil color charts. Hence, it is necessary for pedologists to interpolate between color chips. The matching of a soil sample with a color chip is subjective and depends on the sensory and psychological peculiarities of the observer. Pomerening and Knox (17) concluded that, given favorable conditions, the interpolation of Munsell notations are technically feasible as

${ }^{1}$ Contribution No. R1, Saskatchewan Institute of Pedology.

Can. J. Soil Sci. Val. 46 (1966) 
long as they are no more refined than 1.0 unit for Munsell hue and 0.5 unit for Munsell value and chroma. These observations agree with those recommended by the U.S.D.A. soil survey manual (19); however, experience indicates that under field conditions it is difficult to consistently maintain this level of interpolation. Precise color measurements may be obtained from spectroreflectance measurements of the physical stimuli responsible for the sensation $(2,15)$; the results are then independent of the observer's vision.

This investigation was conducted to assess the magnitude of the variability of soil color measurement among different observers and to study the application of the spectroreflectance technique to the measurement of soil color. The measured color attributes of samples from representative zonal Ap horizons were then evaluated in terms of the limits currently used for the respective Great Group soils (11).

\section{MATERIALS AND METHODS}

\section{Sample Selection}

Representative bulk samples were taken from the Ap horizons of selected Orthic Chernozemic, Orthic Gray Wooded, and Dark Gray Wooded profiles considered to be representative of soils occurring within the Brown, Dark Brown, Black, and Gray Wooded soil zones of Saskatchewan (5). The samples taken from the Ap horizons of the profiles considered to belong to the Dark Gray Chernozemic and Dark Gray Wooded Great Groups were taken from the southern fringe of the Gray Wooded soil zone in a region considered as transitional between grassland and forest (6); they are subsequently referred to as transition Chernozemic - Gray Wooded samples.

The sites were selected in areas of gently and moderately sloping, medium textured, moderately calcareous, glacial till. The samples were taken from soils which occurred on the well-drained midslope position of areas mapped as Haverhill, Weyburn, Oxbow, Whitewood, Waitville, and Loon River Soil Associations $(5,6)$.

\section{Visual Measurement of Soil Colors}

The color of 20 samples was independently measured in the laboratory under controlled lighting conditions, by 12 observers using Munsell soil color charts. The observers were pedologists and students, all of whom were familiar with, and had previously used the Munsell method; they were instructed to measure the Munsell value $(\mathrm{V})$ of each sample to the nearest unit and then to indicate whether the soil sample was lighter or darker than the chip by recording the nearest half unit of value (V). Munsell chroma (C) was estimated in a similar manner (Table 1 ). The midpoints of the classes so recorded were used to determine the range, mode, mean, and standard deviation for the value $(\mathrm{V})$ and chroma $(\mathrm{C})$ of each sample.

\section{Spectroreflectance Measurement of Soil Colors}

A Bausch and Lomb Spectronic 20 equipped with a reflectance attachment was used in this study (1). Inversion of the unit permitted the light beam to be directly incident on the soil sample, thus eliminating difficulties encountered

'Light given from a portable electric lamp (gas-tube type) which consisted of 2 G.E. 15-watt fluorescent tubes (cool white). 
when reflectance measurements were determined through glass as required when the unit was used in the normal upright position.

The conversion of the reflectance measurements to trichromatic specifications (X, Y, Z, x, y) was facilitated by the use of Bausch and Lomb trichromatic coefficient ${ }^{3}$ computing form for illuminant $C(1)$. The results were then expressed in terms of C.I.E. color notations ( $Y, x, y)$ which were converted to Munsell renotation hue, value, and chroma $(12,14,18)$. The colors determined by spectroreflectance measurements were expressed in terms of Munsell renotations (Hre Vre/Cre), whereas colors measured visually by comparison with Munsell color chips were expressed in terms of Munsell notations ( $H$ $\mathrm{V} / \mathrm{C})$.

\section{RESULTS}

\section{Variability of Visual Color Measurement}

Visual estimations of Munsell value by 12 observers for each of the 20 samples showed a variation of from 0.5 to 2.0 units; the average variation was 1.0 unit (Table 1). The standard deviations of the value (V) recorded by each of the 12 observers for each of the 20 samples ranged from 0.28 to 0.55 units, the average of which was 0.39 units. The variations in chroma (C) as determined among the 12 observers showed similar trends, ranging from 0.5 to 1.75 units, with an average variation of 0.94 units. The standard deviations of the chroma (C) recorded ranged from 0.17 to 0.59 , the average of which was 0.35 units.

\section{Comparison of Visual and Spectroreflectance Color Measurements}

Comparison of the results of visual and spectroreflectance methods (18) of color determination (Table 1) indicates that the mean difference between the renotation value (Vre) and the average value $(V)$ for the samples from the Brown, Dark Brown, and Black soil zones was less than 0.1 unit. The differences among samples from within the Gray Wooded soil zone were generally 0.2 units or less. The mean difference between the renotation chroma (Cre) and the average chroma (C) of the Chernozemic (Brown, Dark Brown, and Black) and the Gray Wooded samples was 0.2 and 0.4 units respectively.

\section{Munsell Color Attributes of Sampled Ap Horizons}

Spectroreflectance measurements of 35 samples (including those listed in Table 1) taken from Ap horizons were plotted on the appropriate hue-chroma and value-chroma diagrams (Figs. 1 and 2). The renotation hue of air-dry samples ranged from 9.70YR to $3.75 \mathrm{Y}$ (Fig. 1) with a mean and a mode of $1.25 \mathrm{Y}$. There is no relationship evident between the hue and the soil zone from which the sample was taken. The renotation values of the air-dry samples taken from the Brown soil zone ranged from 4.1 to 4.6 with a mode and a mean of 4.2 and therefore fall within the limits definitive of Dark Brown soils (Fig. 2(a)). The renotation value of the samples from the Dark Brown and Black soil zones ranged from 3.5 to 3.9 and from 2.8 to 3.3 respectively (Fig. $2(a))$. When measured moist, the renotation values of the samples from the Brown, Dark Brown, and Black soil zones ranged from 0.9 to 3.0 (Table 1) and conform with the moist color criteria definitive of Chernozemic soils (11).

\footnotetext{
${ }^{3}$ Alternatively referred to as trilinear coordinate.
} 


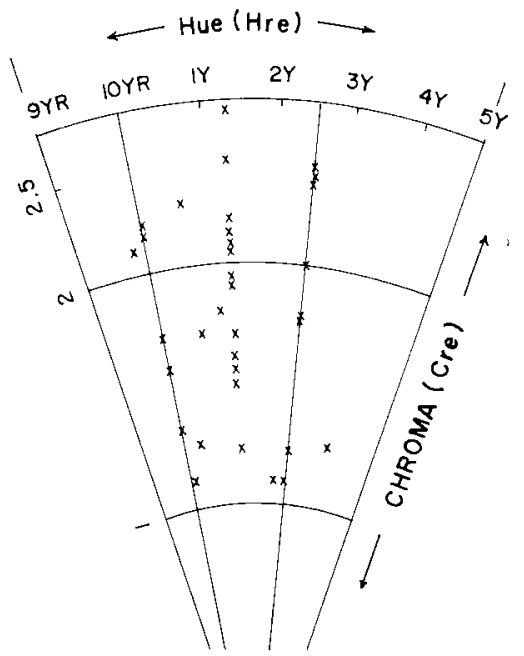

FIG. 1. The distribution of the color of Ap horizons (air-dry) according to Munsell hue (Hre) and chroma (Cre).

The renotation value of the dry samples taken within the transition Chernozemic - Gray Wooded region (Fig. 2(b)) occurred within the limits suggested for Black, Dark Gray Chernozemic, and Dark Gray Wooded soils; the range in measured value was indicative of the color variability present in the transition region. When measured moist, the value (Vre) of the samples taken from within the Gray Wooded soil zone ranged from 1.1 to 3.6 (Table 1).
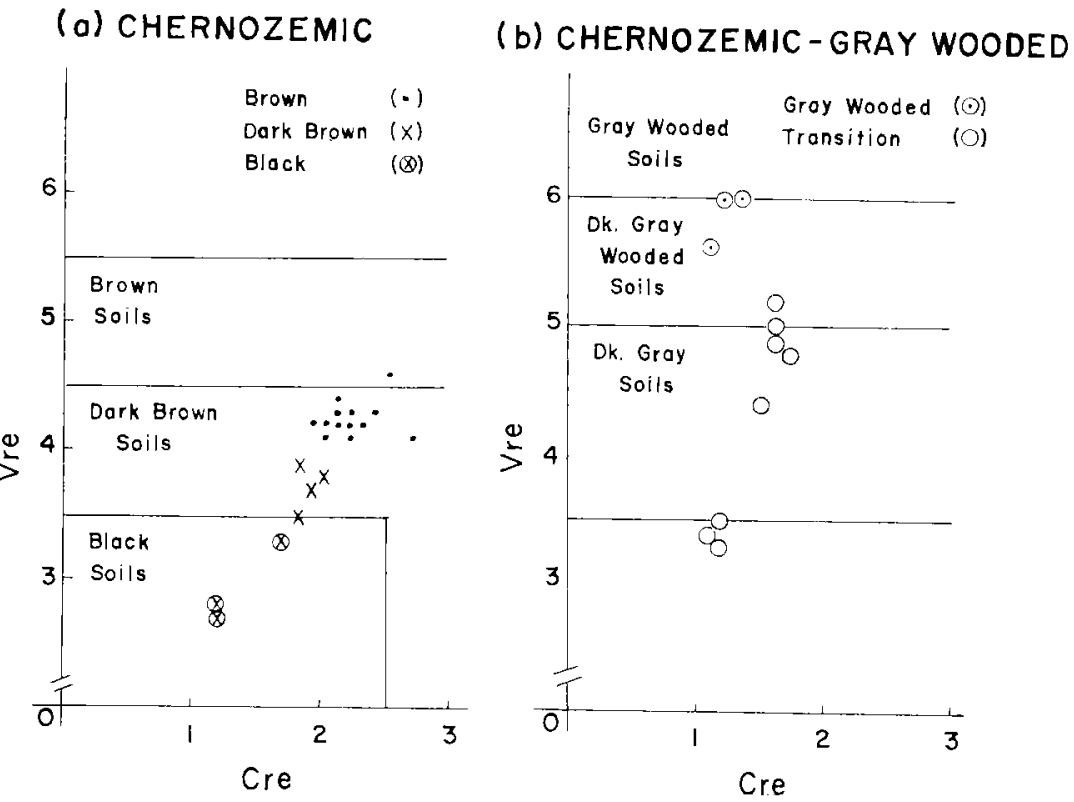

FIg. 2. Munsell value (Vre) and chroma (Cre) for Chernozemic, transition ChernozemicGray Wooded and Gray Wooded Ap horizons (air-dry) in relation to the definitive color
boundaries for Great Group soils. 


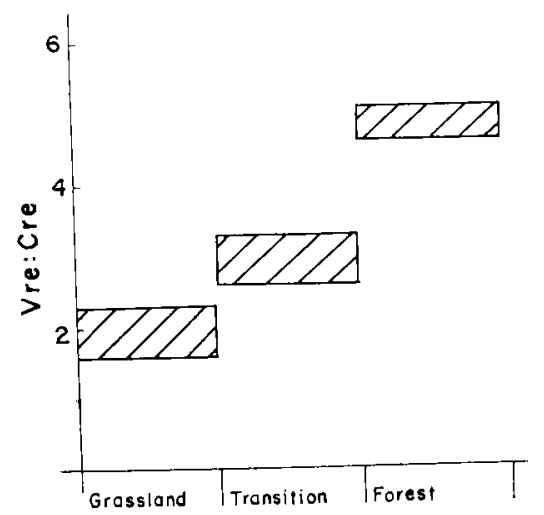

Fig. 3. The range of Vre:Cre ratios of Ap horizons (air-dry) developed under different types of vegetation.

Further characterization of the measured samples was achieved by expressing the color attributes according to the ratio of renotation value : renotation chroma (Vre:Cre) (Fig. 3). The ratios for the soils developed under grassland vegetation (Brown, Dark Brown, and Black soils) were relatively narrow (1.6 to 2.3) compared with the wide ratios (4.5 to 5.1) exhibited by the Gray Wooded soils developed under trees. The ratios of the samples from the transition grassland-forest region were intermediate (2.6 to 3.3$)$ to the above samples.

Comparison of the renotation value of the dry and moist samples indicated variations in the decrease in value due to moisture. The average decrease in value (Vre) among the Brown, Dark Brown, and Black soil samples was 1.9 units, whereas the effect of moisture on the transition Chernozemic - Gray Wooded and Gray Wooded samples resulted in an average decrease of 2.5 units.

\section{DISCUSSION AND CONCLUSIONS}

The recorded variations in the visual estimation of soil color by different individuals indicate that serious errors may result in the application of soil color criteria currently used in the Canadian classification system. The errors are of sufficient magnitude to enable a particular soil to be classified differently by different mappers. The present study has shown that if soil color is to continue to play a definitive role in soil classification, it is important that a more precise method of color measurement be used. Recent investigations into the measurement of soil color (18) have shown that the instrumental nature of the spectroreflectance method is not subject to the error caused by sensory and psychological peculiarities among different observers; the spectroreflectance technique facilitates the measurement of soil color with a precision of 0.1 unit for Munsell renotation value and chroma.

Results of this study indicate that Munsell renotation value and chroma (Vre/Cre) determined from spectroreflectance measurements are similar to the average of the Munsell notation value and chroma (V/C) estimated visually by 12 observers which substantiates the adaptability of the instrumental method 
for the measurement of soil color. The accuracy and precision of the spectroreflectance technique makes it possible to use these data in a number of ways for the characterization of the color attributes of surface horizons.

The hue of most of the samples occurs between the 10YR and $2.5 \mathrm{Y}$ hue charts currently available in the Munsell soil color chart series. This suggests that an intermediate hue chart such as $1.25 \mathrm{Y}$ (which is not available at present) would provide a better color match for the hue of the samples selected from this region and confirms field observations by pedologists who have frequently noted the intermediate hue of well-drained soils of the Northern Great Plains of Canada.

The Vre:Cre ratios segregated the samples into three distinct groups according to whether they were developed under grassland, transition grasslandforest, or forest vegetation. The intermediate ratios (2.6 to 3.3) of the transition samples are presumably a reflection of the characteristics indicative of degradation or of other modification resulting from the accumulation and decomposition of forest litter. The wide ratios (4.6 to 5.1) of the samples taken within the Gray Wooded zone are indicative of the operation of morepronounced degradative processes. There is little doubt that the Vre:Cre ratios determined from spectroreflectance measurements will serve as useful criteria for the characterization of the surface color of Chernozemic and Gray Wooded soils.

Color measurements of cultivated surface samples taken within the various soil zones of Saskatchewan indicate discrepancies between their renotation values and the color criteria suggested for the respective soils at the Order and Great Group levels by the National Soil Survey Committee of Canada. For dry samples from within the Brown soil zone the renotation value is lower than that suggested for Brown soils and fall within the limits definitive of Dark Brown soils. This would suggest the need for a critical examination of the color criteria now used for the separation of Brown and Dark Brown soils at the Great Group level.

The decrease in renotation value due to the presence of moisture is not uniform for all samples as soils of low chroma undergo a greater decrease in renotation value due to moisture than soils of higher chroma. The presence of moisture causes a reduction in the renotation value of Gray Wooded soils from 5.5 when dry, to 3.0 when moist; consequently, they fall within the moist color limit definitive of Chernozemic soils. This suggests that these soils may be defined in terms of either their color when dry or their color when moist, but not both.

\section{REFERENCES}

1. Bausch And Lomb Incorp. 1963. Spectronic 20 colorimeter-spectrophotometer, reflectance attachment, accessories, reference manual. Bausch and Lomb Incorp.,
Rochester 2, N.Y.

2. Carter, W. T. 1931. Color analysis with spectrophotometer. Am. Soil Surv. Assoc.
Bull. 12, 169-170.

3. Evans, R. M. 1948. An introduction to color. John Wiley and Sons, Incorp., New York; Chapman and Hall Ltd., London.

4. Hutron, J. G. 1928. Soil colors, their nomenclature and description. Proc. and Papers 1st Intern. Congr. Soil Sci. 4, 164-172.

5. Mrtcheld, J., Moss, H. C., and Clayton, J. S. 1944. Sask. Soil Surv. Rept. No. 12. 
6. Mitchell, J., Moss, H. C., and Clayton, J. S. 1950. Sask. Soil Surv. Rept. No. 13.

7. Munsell, A. H. 1947. A color notation, Ed, 10. Munsell Color Co., Incorp., Baltimore.

8. Munsell Color Co. Ivcorp. 1941. Soil color charts prepared by T. D. Rice, D. Nickerson, A. M. O’Neal, and J. Thorp. Munsell Color Co., Incorp., Baltimore.

9. Munsell Color Co., Incorp. 1948. Munsell soil color charts. Baltimore, Md.

10. Munseli. Coror Co., Inconp. 1950. Munsell soil color charts, special form for use by Soil Scientists, Geologists and Archaeologists. Baltimore, Md.

11. National Soll Survey Committee (Canada). 1963. Rept. 5th Natl. Meet., Winnipeg.

12. Newhali, S., Nickerson, D., and Judd, D. B. 1943. Final rept. O.S.A. subcommittee on the spacing of the Munsell colors. J. Opt. Soc. Am. 33, 385-418.

13. Nickerson, D., Kelly, K. L., and Stultz, K. F. 1945. Color of soils. J. Opt. Soc. Am. 35, 297-300.

14. Nickersos, D. 1946. Color measurement and its application to the grading of agricultural products. U.S. Dept. Agr. Misc. Publ. 580.

15. Opticai Society of America, Committee on Colorimetry. 1953. The science of color. T. Y. Crowell Co,, New York.

16. Pendetor, R. L. and Nickerson, D. 1951. Soil colors and special soil color charts. Soil Sci. 71, 35-43.

17. Pomerening, J. A. and Knox, E. G. 1962. Interpolation of Munsell soil color measurements. Soil Sci. Soc. Am. Proc. 26, 301-302.

18. Shelos, J. A. 1964. Application of trichromatic analysis and organic matter fractionation to the study of soil color. M.Sc. Thesis, Univ. of Saskatchewan.

19. Son Survey Staff. 1951. Soil survey manual. U.S. Dept. Agr. Handbook 18.

20. Winters, E. 1930. The measurement of soil color. Am. Soil Surv. Assoc. Bull. 11, 34-37. 